\section{Conjugated Serotonins Related to Cathartic Activity in Safflower Seeds (Carthamus tinctorius L.)}

\author{
Sadao Sakamura, Yoshihiko Terayama, \\ Satomi KawaKatsu, Akitami IchiHara \\ and Hideya SAITo* \\ Department of Agricultural Chemistry, \\ Faculty of Agriculture, Hokkaido \\ University, Sapporo 060, Japan \\ *Department of Pharmacology, Hokkaido \\ University, School of Medicine, \\ Sapporo 060, Japan \\ Received June 23, 1978
}

Recent studies on the isolation of cathartic lignan glycoside ${ }^{1 \prime}$ from Carthamus tinctorius L. prompt us to report our results in a related area. Ethyl acetate extracts from oil-free safflower meal $(3 \mathrm{~kg})$ were chromatographed on silica gel columns to give three new serotonin derivatives $1(2.22 \mathrm{~g}), 2(1.32 \mathrm{~g})$ and $3(0.55 \mathrm{~g})$, all of which showed positive response for the both Folin-Ciocaltheu's and Ehrlich's reagents.

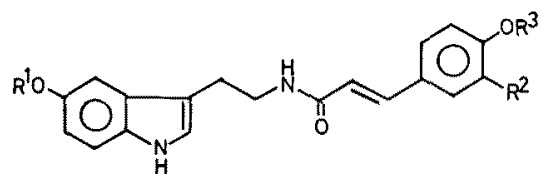

$\begin{array}{cccc} & \mathrm{R}^{1} & \mathrm{R}^{2} & \mathrm{R}^{3} \\ (\text { I) } & \mathrm{H} & \mathrm{OCH}_{3} & \mathrm{H} \\ (2) & \mathrm{H} & \mathrm{H} & \mathrm{H} \\ (3) & \beta \text {-D-glucose } & \mathrm{H} & \mathrm{H} \\ (4) & \mathrm{Ac} & \mathrm{OCH}_{3} & \mathrm{Ac} \\ (5) & \mathrm{Ac} & \mathrm{H} & \mathrm{Ac}\end{array}$

Spectroscopic evidences showed that $1, \mathrm{mp}$ $117.2 \sim 119.3^{\circ} \mathrm{C}, \mathrm{C}_{20} \mathrm{H}_{20} \mathrm{~N}_{2} \mathrm{O}_{4}$ was an acylserotonin containing sec. amide group [IR $\nu_{\max }^{\mathrm{KBr}}$ $\left.\mathrm{cm}^{-1}: 1660\right]$, tryptamine moiety [PMR $\delta_{\mathrm{TMS}}^{\mathrm{C}_{3} \mathrm{D}_{8} \mathrm{O}}$ : $2.94(2 \mathrm{H}, \mathrm{t}, J=7 \mathrm{~Hz}), 3.65(2 \mathrm{H}, \mathrm{q}, J=7 \mathrm{~Hz})$, $\mathrm{CH}_{2}-\mathrm{CH}_{2}-\mathrm{N}$ ] and feruloyl moiety [PMR $\delta_{\mathrm{TMS}}^{\mathrm{C}_{3} \mathrm{D}_{6} \mathrm{O}}$ : $3.88\left(3 \mathrm{H}, \mathrm{s}, \mathrm{OCH}_{3}\right), 6.54,7.52(2 \mathrm{H}$, each d, $J=16 \mathrm{~Hz}, \mathrm{HC}=\mathrm{CH})]$. The mass spectrum of 1 exhibited a base peak at $m / e 146$ due to fragment ion $a$, which arises from serotonin part. Spectroscopic data of 2, mp 193.6 $194.5^{\circ} \mathrm{C}, \mathrm{C}_{19} \mathrm{H}_{18} \mathrm{~N}_{2} \mathrm{O}_{3}$, were very similar to those of 1 except absence of a signal due to $\mathrm{OCH}_{3}$ in the PMR spectrum. Acetylation of each of 1 and 2 with acetic anhydride in pyridine gave diacetates, $4, \mathrm{mp} 72.7 \sim 76.5^{\circ} \mathrm{C}$ and $5, \mathrm{mp}$ $153.2 \sim 155.2^{\circ} \mathrm{C}$. Hydrolysis of 1 and 2 with $\mathrm{NaOH}$ afforded ferulic acid and p-coumaric acid respectively. From the evidences mentioned above, the structures for the compounds were deduced to be $\mathrm{N}$-feruloylserotonin $(I)$ and $\mathrm{N}$-p-coumaroylserotonin (2). ${ }^{13} \mathrm{C}$-NMR spectrum of 2 is unambiguously assigned as illustrated in Fig. 1. Validity of these structures was obtained by the synthesis of their acetates 4 and 5, starting from serotonin and feruloyl acetate or coumaroyl acetate.
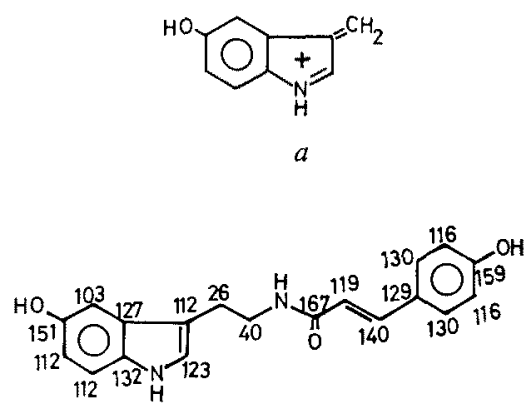

FIG. 1. ${ }^{13} \mathrm{C}-\mathrm{NMR}$ spectrum of 2 measured in acetone-d $d_{0}$ Chemical shifts were expressed by $\delta$ from TMS.

The third compound $3, \mathrm{mp} 228.0 \sim 230.2^{\circ} \mathrm{C}$, was also shown to be an acylserotonin derivative by its spectroscopic data [IR $\nu_{\max }^{\mathrm{KBr}} \mathrm{cm}^{-1}$ : $1660 ;$ PMR $\delta_{\mathrm{TMS}}^{\mathrm{C}_{3} \mathrm{D}_{6} \mathrm{O}_{6}} ; 6.45,7.40(2 \mathrm{H}, \mathrm{ABq}$, $J=16 \mathrm{~Hz}), 6.32,7.20(4 \mathrm{H}, \mathrm{ABq}, J=9 \mathrm{~Hz})]$. The compound 3 was converted to a pentaacetate, mp $172.9 \sim 174.0^{\circ} \mathrm{C}, \mathrm{C}_{35} \mathrm{H}_{38} \mathrm{~N}_{2} \mathrm{O}_{13}$, by acetylation, and hydrolysed to $\mathrm{N}$-p-coumaroylserotonin 2 and $\mathrm{D}$-glucose with dilute $\mathrm{HCl}$ or $\beta$-glucosidase. Since methylation of 3 with diazomethane and subsequent hydrolysis afforded $p$-methoxycinnamic acid, D-glucose must be located at $5-\mathrm{OH}$ in serotonin portion, and the structure was determined as N-pcoumaroylserotonin- $\beta$-D-glucopyranoside.

Though no appreciable physiological activities of the new conjugated serotonins, 1, 2 
and 3 on rabbit intestines using Magnus' method were observed, 2 was easily hydrolysed to $p$-coumaric acid and serotonin in rabbit liver homogenate. Since serotonin ${ }^{2)}$ is noted as a physiologically active compound including cathartic activity on the intestines, the conjugated serotonins would exhibit physiological activities in combination with originally present 2-hydroxyarctiin and serotonin $(40 \mu \mathrm{g} / \mathrm{g}$ in the meal, estimated according to Udenfriend's procedure) $^{31}$ This is the first report for conjugated serotonins. ${ }^{4}$

\section{REFERENCES}

1) R. Palter, R.E. Lundin and W.F. Haddon, Phytochemistry, 11, 2871 (1972).

2) W. Lovenberg, J. Agric. Food Chem., 22, 23 (1974).

3) S. Udenfriend, M. Weissbach and C.T. Clark, J. Biol. Chem., 215, 337 (1955).

4) T. A. Smith, Phytochemistry, 14, 865 (1975). 